\title{
"Lugares da memória" no Estado do Paraná: demandas e políticas pela preservação do patrimônio cultural
}

\author{
Teresa Jussara Luporini*
}

\begin{abstract}
RESUMO
A sociedade brasileira vive entre a falta de uma política cultural por parte das autoridades constituídas e a onda de preservação de diferentes memórias por variados segmentos da população. A investigação apreende um dos momentos deste contexto, enfocando a preservação da memória como possibilidade de reinterpretação do passado, na constituição do espaço vivencial, no cotidiano e no presente. Analisa a política cultural formulada e adotada pelo governo do Estado do Paraná, na gestão 1991-1994. Recorta, metodologicamente, a política setorial da área da cultura optando pela análise das ações desenvolvidas, no âmbito da preservação, que apontam para a constituição de um inventário de bens culturais destinado a manter/consolidar a identidade cultural paranaense e, neste sentido, criando "lugares da memória". Por meio da análise documental em registros oficiais, interlocução com os atores sociais envolvidos - autores, gestores e agentes de coleta de dados contatados, direta ou indiretamente via entrevista e questionários -, verificouse como as ações foram postuladas, a nível do discurso e, se a postura assumida pelo governo respondeu a demandas, existentes ou emergentes, na sociedade paranaense. Constatou-se que ocorreu a criação de um espaço para o surgimento/implementação da consciência preservacionista nos municípios paranaenses atingidos pela proposta governamental, embora não se tenha efetivamente colaborado para a democratização da cultura e a socialização do conhecimento, nos níveis idealizados pela política oficial. Evidenciou-se que a questão patrimonial está articulada à questão cidadã e é a formulação de políticas culturais de inspiração democrática que afasta o enfoque conservador, xenófobo, saudosista para dar lugar à consciência do uso social do
\end{abstract}

* Professora da Universidade Estadual de Ponta Grossa - Doutora em Educação.

Olhar de professor, Ponta Grossa, 1(1):115-128, out. 1998. 
patrimônio cultural, permitindo a democratização dos espaços culturais e a s socialização do conhecimento da realidade patrimonial paranaense.

Palavras-chave: políticas públicas, patrimônio cultural, educação patrimonial, preservação da memória

A preservação do patrimônio cultural ainda não é vista pela sociedade brasileira e, especialmente, pelas autoridades constituídas, como um fator primordial diante das formidáveis tarefas de se permitir acesso à educação, habitação e saúde à maioria da população.

Entretanto, é preciso refletir sobre a possibilidade de se implementar de alguma forma a discussão sobre o resgate e preservação de diferenciadas memórias que são explicativas do "modus vivendi" das comunidades espalhadas pela imensidão do território brasileiro.

A compreensão do modo como essas comunidades se constituíram e desenvolveram, em passado próximo ou remoto, pode explicitar as relações de poder que são vigentes até os dias atuais e que se constituem em obstáculos às tentativas de mudança de determinadas estruturas sociais, reprodutoras das tremendas desigualdades que assolam a população brasileira.

Embora não exista uma política oficial consistente, nunca se assistiu como atualmente, a uma onda de preservação da memória das famílias (especialmente de imigrantes), das instituições, dos caminhos, das ruas, das praças e jardins, dos bairros, das an- tigas fábricas, estações ferroviárias desativadas, das festas e comemorações, dos prédios e monumentos e de tantos outros símbolos da presença material do homem, tanto por parte das autoridades constituídas quanto de segmentos da sociedade civil.

Esta investigação procura apreender um dos momentos desse contexto, enfocando a preservação da memória como possibilidade de reinterpretação do passado na constituição do espaço vivencial, no cotidiano e no presente.

$\mathrm{O}$ estudo buscou o entendimento das práticas de governo na área cultural, ao constituir um espaço de poder pela produção de uma série de documentos que constroem um discurso sobre o tema da preservação da memória.

Para tanto, foi analisado o plano de ação do Estado, estabelecendo os indicativos de sua concepção e execução, uma vez que foi somente nesta década que, pela primeira vez, o governo paranaense criou um programa que objetivou a elaboração de um inventário de bens culturais que atingiu significativa "amplitude territorial e temática", e, segundo sua ótica, privilegiou os eixos de democratização, descentralização, socialização e preservação da identidade paranaense. 
Pretendeu-se verificar como as ações foram postuladas em nível do discurso e indicar se a postura que o Estado assumiu responde a demandas criadas, existentes ou emergentes na sociedade paranaense. Para tanto, analisou-se especialmente a política setorial desenvolvida pela Coordenadoria do Patrimônio Cultural da Secretaria de Estado da Cultura - SEEC/PR.

A tentativa de intelegibilidade do projeto governamental representou uma opção metodológica pois examinou a política cultural paranaense apenas pela ótica da questão patrimonial, um dentre os aspectos que a caracterizam; procedeu à análise do projeto governamental procurando aprender se os fundamentos da proposta cultural estão articulados com princípios democráticos destinados à preservação patrimonial.

Por meio das intenções contidas no projeto e ação governamental e da percepção construída em função dos dados coletados, procurou esboçar os desafios e as opções para a formulação de uma política cultural, de inspiração democrática, fundamentada na participação social.

A busca dessa percepção está articulada à existência de elementos que caracterizam o crescimento da cons- ciência em relação ao patrimônio, não só no Brasil, como em toda a América Latina.

O primeiro deles é o seu caráter abrangente que se manifesta na própria conceituação do termo, que passa de patrimônio histórico para patrimônio cultural. Isso denota um distanciamento de um enfoque limitador, centrado em aspectos apenas históricos, estéticos e oficiais, e uma aproximação com outras áreas que passam a qualificar o termo patrimônio - edificado, natural, antropológico, urbano, ecológico, científico e outros - resultando, portanto, na expressão patrimônio cultural, que não deixa de incluir o histórico ${ }^{1}$. Este novo conceito passa a direcionar as ações de preservação que começam a contemplar outros tipos de edificações - que não apenas as construções oficiais, eclesiásticas e da sociedade dominante - mas, também, aquelas que testemunham as atividades cotidianas do homem de diferentes segmentos sociais, assim como suas manifestações de saber, fazer e lazer (esta postura marcadamente da última década).

Especialmente no que se refere às discussões sobre patrimônio histórico, observa-se que o desenvolvimen-

\footnotetext{
${ }^{1}$ A este respeito ler MAgnani, José C. Pensar grande o patrimônio cultural.LuA NOva, 19--; Hughes de VARINE-BOHAN, professor francês e técnico internacional dauNESCO, pioneiramente expressou a preocupação em visualizar a questão do Patrimônio Cultural na perspectiva abrangente e interdisciplinar, dividindo-o em três grandes categorias: elementos pertencentes à natureza (recursos naturais/habitat natural); ao conhecimento (técnicas; ao saber, ao saber-fazer); bens culturais propriamente ditos (objetos, artefatos, construções).
} 
to urbano, mercantilização, as indústrias culturais e o turismo são visualizados como ameaças aos atuais processos de mudança.

CANCLINI(1994) indica que tais aspectos devem ser concebidos como contextos onde atualmente se inserem o patrimônio histórico e a identidade nacional, marcados pelos "processos de urbanização, industrialização e massificação da cultura, as migrações e a transnacionalização de bens materiais e simbólicos, a globalização e as formas de integração econômica", que redefinem a conceituação do que se infere por nação (p.95).

A mudança dessa concepção está articulada a uma posição de que a nação extrapola o conjunto de bens e tradições originárias, mantidos em limites geográficos onde historicamente se localiza uma população. Isto porque seus habitantes mantêm relações de intercâmbio com outros países via estrangeiros ou imigrantes, tanto diretamente quanto via novos meios de comunicação, reproduzindo, assim, por diferentes formas, a cultura nacional.

Nessa perspectiva, as linguagens como rádio, televisão, cinema, vídeos e discos se convertem em meios estratégicos para o registro e divulgação cultural da própria comunidade que os criou, integrando o patrimônio, embora de forma diferente de outros bens culturais tradicionalmente considerados, mas extremamente importantes no mundo atual, caracterizado pela presença maciça desses novos meios, o que exige uma reconceitualização do patrimônio cultural.

Daí decorre a ampliação do conceito de patrimônio, considerando a apropriação de conhecimento via indústria cultural, as novas tarefas para as políticas culturais em razão dos possíveis usos sociais do que foi produzido no passado e da incorporação ao patrimônio de produtos da cultura popular.

O segundo aspecto que caracteriza o crescimento da consciência preservacionista é a mudança de "escala da noção de patrimônio", que passou da obra singular ao conjunto urbano ou territorial". Desse modo ocorre, também, a mudança na "metodologia e na problemática abordada" (Cf. Gutierrez, 1992, p. 121). Significa dizer que não basta mais tentar a preservação, via decreto, de prédios do poder constituído, mas tentar impedir a destruição do patrimônio construído via conscientização das populações e da racionalização do crescimento urbano. Assim, as iniciativas de intervenção passam a considerar a ação das comunidades e a encarar o patrimônio construído como um "capital concentrado" passível de ser reutilizado para habitação de seus moradores atuais, evitando o enfoque exclusivamente turístico.

Observam-se, nesse aspecto, duas questões distintas: a possibilidade concreta de intervenção de diferentes segmentos da população e a consciência dessa mesma população de que 
pode interferir na definição das estratégias para a preservação e, portanto, para a formulação de políticas culturais.

Nesse sentido, destaque-se a diferenciada capacidade dos diversos grupos sociais de se apropriarem da herança cultural. A participação desigual se reflete na hierarquização dos capitais culturais. Mesmo legislações democráticas de órgãos oficiais que legitimam diferenciados modos de organização e expressão da vida social não evitam o acesso preferencial dos grupos sociais que se colocam hegemonicamente na produção e distribuição dos bens culturais. Assim, a essência da desigualdade na composição do patrimônio coloca a perspectiva de que ele seja estudado como arena política em que se confrontam diferentes visões de classe, etnias e grupos, presentes na sociedade contemporânea.

A atuação popular na definição de perspectivas de preservação esbarra nas tensões entre o saber técnico dos profissionais que atuam na área cultural e as iniciativas de intervenção dos habitantes da cidade, e o que subjaz a essas iniciativas que se vinculam à identidade cultural.

Analisando a riqueza de padrões culturais brasileiros, em seus múltiplos grupos sociais, pode-se inferir que a tarefa de organizar um "conjunto de bens" que seja representativo do país, protegido oficialmente, é tarefa delicadíssima que representa uma opção que serve a interesses determinados.

E é pela explicitação dessa subjetividade na composição do patrimônio cultural "oficial" que atualmente se observa a tentativa de incluir no conjunto de bens nacionais aqueles que representam, de alguma forma, as classes menos favorecidas economicamente, os grupos marginalizados, mas que participaram de maneira efetiva para firmar presença e atuar decisivamente em circunstâncias histórico-político-econômico-sociais, no passado e/ou no presente. ${ }^{2}$

JEUDY (1990), refere-se a esse movimento refletindo sobre os limites do patrimônio, os quais são estabelecidos por "critérios históricos estéticos" e que podem privilegiar monumentos e obras de arte em detrimento de objetos considerados de menor significância, o que já representa uma seleção, opção.

Sua reflexão vai mais além, ao indicar que a questão atual sobre o sentido do patrimônio não está volta-

${ }^{2}$ WILLIANS apud CANCLINI (1994) indica que o processo social de desenvolvimento do patrimônio engloba três dimensões a serem consideradas: o arcaico "que pertence ao passado" e é reconhecido como tal por quem hoje o revive; (...) o residual se formou no passado, mas se encontra em atividade dentro de processos culturais; o emergente designa novos significados e valores, novas práticas e relações sociais (p. 108). 
da, exclusivamente, para o que denomina de "monumentalidade, ${ }^{3}$ mas que se direciona para uma nova perspectiva que se configura na "valorização das memórias coletivas". Tal posicionamento se expressa ao ultrapassar os signos que representam o nobre, o religioso, o estético - "castelos, igrejas, obras de arte" - para considerar o que reflete as atividades econômicas - "objetos artesanais, industriais e agrícolas" - e os modos de viver, pensar e comunicar. Deixa, assim, de considerar como função patrimonial apenas a guarda e conservação de objetos representativos/ evocativos do passado, para investir no presente.

Neste aspecto, enquanto espaço de competição econômica, política e simbólica os usos do patrimônio estão assinalados por uma tripla dimensão: a ação privada, o Estado e os movimentos sociais. Esses usos são caracterizados conforme a perspectiva de interação entre as três dimensões.

Isso se dá porque, no que se refere ao setor privado, sua atuação normalmente se expressa pelo uso desordenado dos recursos ambientais e do espaço urbano, pela fúria especulativa imobiliária, em prejuízo dos bens culturais e dos interesses de parcelas majoritárias da população. Tais procedimentos derivam de dife- rentes tipos de organizações tanto do setor industrial e do imobiliário como do turístico, que tratam o patrimônio pela lógica competitiva. Sua atuação só pode ser freada se existirem propostas oficiais que zelem pelo patrimônio, enquanto um bem público, definindo a regulação do desenvolvimento econômico setorizado, no sentido de proteger interesses coletivos.

No que se reporta à atuação do Estado, sua relação com o patrimônio é contraditória, porque ao mesmo tempo que o qualifica como representação da nacionalidade - agindo institucionacionalmente ao recuperar sítios arqueológicos e centros históricos, criando museus, publicando materiais voltados à preservação da memória - o utiliza como recurso para a criação de uma identidade comum, compartilhada, diluindo especificidades e conflitos de sua variada composição. Neste aspecto registra-se a presença dos movimentos sociais que, junto ao governo, traduzem a direção que o Estado deveria assumir na preservação patrimonial.

Os movimentos sociais têm se destacado na defesa do patrimônio edificado, urbano e ambiental, ocupando um espaço ainda pouco considerado pela política cultural. Porém, a criação de uma consciência coletiva em relação aos usos sociais do

${ }^{3}$ Monumentaliadade - o termo utilizado para indicar monumentos históricos que definem "uma ordem simbólica do passado". 
patrimônio está longe de ser uma realidade. A mobilização popular, que tem se mostrado competente em situações de crise, tende a diminuir quando elas são solucionadas ou amenizadas, uma vez que as classes menos privilegiadas da população são obrigadas a enfrentar diuturnamente as questões mais imediatas do cotidiano.

Apesar disso, em suas diferentes vertentes, os movimentos sociais vêm contribuindo para uma mudança de posicionamento do setor público, especialmente porque a questão do patrimônio tende a ser visualizada, não somente como atribuição governamental, mas como responsabilidade dos diferentes segmentos sociais mobilizados por contingências cotidianas comuns. Assim, a apropriação democrática do patrimônio depende da criação de condições materiais para que os diferenciados grupos sociais possam nele encontrar uma significação, compartilhando-o (cf. CANCLINI, 1994, p.95-114).

Em tal enfoque, o objetivo de uma política cultural deixa de ser apenas a preservação do passado para converter-se na ampliação do espaço de participação no presente, o que envolve o espaço da cidadania ${ }^{4}$. Esta, entendida não só no seu suporte jurídicoinstitucional, mas como possibilida- de de realmente fazer valer os direitos definidos em lei, criando novas possibilidades de interferência na realidade cotidiana.

Nesse sentido, o indivíduo deixa de ser apenas alvo do estatuto jurídico para converter-se em cidadão, ativo no universo político, como sujeito que reivindica e que pode influenciar, em maior ou menor grau, a mudança social.

$\mathrm{Na}$ perspectiva do exercício da cidadania, a articulação entre a constituição do patrimônio e as políticas preservacionistas são extremamente atuais e fundamentais no contexto contemporâneo porque, nas últimas décadas, em nível planetário, vem se concretizando uma política preservacionista, especialmente no que se refere aos aspectos ecológicos. Nesta concepção a preservação de bens culturais/naturais se coloca como fundamento para a garantia de direitos universais que ultrapassam especificidades nacionais/locais. Assim, as políticas culturais vêm perseguindo a incorporação de perspectivas cidadãs e de garantia de direitos culturais.

Enquanto sujeito do contexto sócio-político, o cidadão colabora para a construção de uma outra historicidade, que não aquela imposta pelo patrimônio tradicionalmente conside-

\footnotetext{
${ }^{4} \mathrm{O}$ termo entendido como conjunto de direitos civis, políticos e sociais aos quais correspondem a cidadania civil - liberdade individual e direito à justiça -, a cidadania política - exercício de participação na esfera política (eleições, etc...) -, e a cidadania social - direito ao bem estar, à segurança, à educação e cultura, à previdência e assistência social (cf. MARSHAL, T. H. Cidadania, status e classe social).
} 
rado, a qual permita a formulação de uma nova linha de intelegi-bilidade, não só do passado, mas das lutas cotidianas no presente. São essas lutas que podem garantir-lhe os seus direitos culturais, inseridos em sua cidadania social; direitos que devem permitir a ele tanto a sobrevivência quanto o direito à memória, a criação e o acesso aos bens culturais, o que necessariamente envolve as questões da memória e da identidade cultural.

Justamente por tais razões o estudo da memória, enquanto possibilidade de vestígio, de registro que se faz e refaz na riqueza da experiência humana, tem sido alvo do interesse da discussão historiográfica na tentativa de criar campos documentais baseados em seu registro. Isto se dá porque a memória é visualizada tanto no seu caráter seletivo - ao privilegiar determinados registros -, como ao seu caráter de criação - porque pode ser produzida com objetivos bem definidos.

LE GOFF (1990), em seus estudos sobre essa temática, indica que a histeria da sociedade em preservar a sua memória expressa o quanto esta se torna importante. Especialmente para os poderes constituídos, com o objetivo de exercer o controle social. Destaca, com base em NORA (1990), em que medida, na atualidade, a História está pressionada pelas memórias coletivas, a partir dos estudos dos locais onde as mesmas se encontram:

Isto se coloca como imperativo para os governos na atualidade, em função de que a memória é elemento fulcral da identidade, seja individual, seja coletiva, cujo resgate/determinação constitui-se numa das tarefas fundamentais para os indivíduos e para as diferentes sociedades.

A questão da identidade dos diferenciados grupos humanos está articulada aos locais onde se cristaliza e se refugia a memória, a que NORA denomina "lugares da memória". Eles são criados em função da "aceleração da história", em meio dos fenômenos do mundo contemporâneo como a mundialização, a massificação, a mediatização. Os "lugares da memória" materialmente apresentam-se como vestígios, restos, testemunhos do que já passou. Seu tempo é o que se expressa pelo desaparecimento da essência íntima da memória para reviver sob a operação intelectual que constrói a História.

“Os lugares da memória nascem e vivem do sentimento que não há memória espontânea, que é preciso criar arquivos, que é preciso manter aniversários, organizar celebrações, pronunciar elogios fúnebres, notariar atas, porque essas são operações naturais" (NORA, 1993, p. 12). Assim se constituem registros de minorias, apoiados por uma gama de produtores tradicionais de arquivos: as grandes famílias, a igreja e o Estado. Entretanto, a crescente democratização da sociedade, a atual consideração à memória de marginalizados, a valorização de fontes da nova cultura oral contemporânea contribuem para uma 
formidável ampliação da materialização da memória sob a forma de produção de arquivos. É esta ânsia de ir em busca de suas origens, de sua identidade que move diferentes atores sociais na recuperação de memórias particulares. Consagram-se, assim, os "lugares da memória", que coexistem em três dimensões: material, funcional e simbolicamente. A primeira pode ser exemplificada pelo arquivo ao qual se confere aura simbólica; a segunda - um testamento - se for valorizado enquanto ritual; a terceira um minuto de silêncio - que só alcança a dimensão indicada se remete a determinada lembrança. (cf. NORA, 1993). Nesse entrelaçamento, os "lugares da memória" se caracterizam como um movimento que articula Memória e História, pois intencionalmente se busca preservar os vestígios impedindo a ação do esquecimento. A História, ao interpretá-los e devolvê-los à sociedade, os institui simbolicamente.

Para ser coerente, a política cultural do patrimônio articula-se aos sinais que o contexto histórico emite, reconhecendo o que se dimensiona como residual e emergente no processo social de desenvolvimento do patrimônio. O primeiro, residual, porque embora criado no passado, ainda se mantém no presente no processo cultural. O segundo, emergente, porque aponta para novas e atuais perspectivas: significados, valores, práticas e diálogos sociais (cf. CANCLINI, 1994, p. 106/109). Descarta, assim, para compor o patrimônio, o que se coloca unicamente pela tradição e cuja significação não interfere nas relações sociais no presente.

Entende-se, assim, que a tarefa de preservação para ser realizada de forma competente articula-se a diferentes instâncias administrativas em seus níveis federal, estadual e municipal. Entretanto, tal situação só poderá configurar-se concretamente pela via da efetiva descentralização de poder político e de recursos, pela clarificação das políticas desenvolvidas na área cultural, pela democratização dos canais de decisão - fóruns populares com poderes deliberativos -, por legítimos investimentos no setor - tanto do ponto de vista legal, pela criação de legislação pertinente, quanto por destinação apropriada de recursos (a descentralização efetiva) -, pela adoção de diferentes mecanismos de divulgação das ações desenvolvidas por órgãos preservacionistas no sentido de manter/implementar eficientes canais de comunicação com os diferentes segmentos da sociedade.

A participação social na definição patrimonial indica possibilidades educativas, no sentido como são entendidas por GOHN (1992), em suas dimensões de organização política, da cultura política e espacial-temporal.

Abre-se, nesse enfoque, o espaço da educação não-formal pela progressiva aquisição da consciência de direitos e deveres, luta especialmente pelo acesso aos direitos, possibilidade de organização e ação coletiva em 
função da clareza adquirida quanto a forma de funcionamento de órgãos públicos - procedimentos para a obtenção de verbas, agentes envolvidos em sua gestão, identificação de interesses presentes e/ou contemplados , elaboração de demandas representativas dos direitos a conquistar. A trajetória experiencial se revela educativa pela compreensão dos elementos restritivos amparados na tradição, os quais podem ser desmistificados pela sua decodificação; pelo desvelar estratégias de conformismo/resistência fundamentadas na análise da desigualdade social. Tais estratégias expressam condições de vida dos diferentes segmentos sociais no passado e no presente, e explicam o contexto da apropriação de espaços públicos para usos privados.

A participação social possibilita o acesso a uma educação autoconstruída em processo, gerada por diferentes fontes, relacionadas ao exercício do poder em variadas instâncias, institucionais ou não.

No que concerne à educação formal, registra-se que alguns municípios paranaenses já investem na possibilidade de utilização dos patrimônios, enquanto objeto de ensino, de discussão da relação Memória- História. A reflexão sobre a forma como interagem é importantíssima no que se refere à História Local e ao que representa em termos de fontes e de compreensão do modo de pensar e viver local, de conhecimento sobre a identidade cultural.
Tal perspectiva é tanto mais valiosa na medida em que há uma tendência manifesta nos meios educacionais, de valorização do estudo da memória local e uma grande sensibilização quanto às especificidade históricas e culturais do meio originário do aluno. É nesse sentido que RODRIGUES (1982) prega a necessidade de preservação da documentação local e regional, por considerar que a História é de indiscutível contribuição para a Historiografia e as Ciências Sociais.

Para o autor, detalhar o desenvolvimento de uma comunidade é gerar sólida contribuição à História Nacional. Embora limitada pelo perigo da fragmentação, a História Local apresenta os acontecimentos do cotidiano do homem comum coletados nos arquivos das famílias ou das instituições, e na memória dos idosos. Isso supõe para o historiador local ter em mente que os acontecimentos não são obrigatoriamente representativos de uma conjuntura regional ou mesmo nacional. Aceitam-se as suas limitações, seja pela própria natureza do tema ou pela impossibilidade de preencher um quadro histórico em todas as suas implicações conjunturais.

Para CAMPOS (1986), os estudos locais representam material valioso, senão diretamente para os estudos tratados, para a percepção dos costumes, das idéias, da mentalidade vigente na época de sua produção. E cita como exemplo a obra dos poetas românticos José de Alencar e Joaquim 
Manoel de Macedo como fontes de um tempo, testemunhos de um conteúdo que, sem o compromisso metodológico do historiador, retratam de forma espontânea os acontecimentos de sua época.

SAMUEL ressalta que um projeto de História Local pode originar seus próprios arquivos e fontes, numa verdadeira miscelânea de documentos, obtidos nos locais mais improváveis. Também há possibilidade de utilização da "evidência oral" com todas as suas vantagens e mazelas, determinando que "o relatório vivo do passado deve ser tratado com respeito, mas também com crítica; como o morto" (p. 239).

Na perspectiva referendada pelos autores, os arquivos locais passam a assumir fundamental importância pela possibilidade de oferecer múltiplas oportunidades de utilização. Aí se incluem, também, os arquivos escolares.

A utilização dos arquivos, enquanto procedimento de ensino, invoca a consideração tanto por parte do historiador quanto do professor, às características específicas dos variados materiais que o homem produz no seu cotidiano. Ter em mente, também, a forma como o documento se perpetua enquanto memória, estabelecendo um poder decorrente dos significados que encerra.

A produção do saber por alunos, tendo a História Local como objeto de estudo, pode ser uma experiência potencializadora para o currículo es- colar. Currículo encarado como uma forma de arrumar e articular um processo pela busca e confronto de dados pertinentes a uma realidade próxima, que favoreça ao educando uma melhor compreensão das normas sociais, usos, costumes e tradições que regem a comunidade onde vive. Além disso, tais dados podem favorecer a análise das transformações ocorridas, dos avanços e retrocessos verificados e das possibilidades de novas transformações pela ação dos sujeitos sociais.

É uma situação que não se limita apenas ao ensino de História, uma vez que se configura numa busca, por parte dos alunos, de diferentes modos de pensar, enxergar a realidade e expressar suas reflexões a respeito de um objeto de estudo e, conseqüentemente, de uma realidade da vida cotidiana. Revela situações complexas, que permitem encaminhar a discussão para as diferentes relações de trabalho e poder na sociedade brasileira.

Os trabalhos de resgate de memória coletiva, são passíveis de desenvolvimento por duas formas: contando com os documentos de arquivos tais como exposições, organização de museus escolares, coleta de depoimentos, dentre outros; analisando as mais diferentes realidades patrimoniais para estabelecer enriquecedores diálogos com o passado.

Essa postura supõe novas relações da escola com a comunidade: amplo conhecimento dos bens culturais existentes, clareza quanto a capacidade de 
sua utilização (como ponto de partida e não como simples ilustração), estabelecimento de redes explicativas/ con-texto histórico-social em que está inserida (cf. MANIQUE; PROENÇA, 1994).

A possibilidade de desenvolvimento da Educação Patrimonial está posta tanto formal, quanto não-formal e informalmente, pela utilização dos "lugares da memória" como fontes do processo educativo. Estando voltada para questões relacionadas às realidades patrimoniais, a Educação Patrimonial compreende desde a inclusão de conteúdos programáticos nos currículos escolares de todos os níveis de ensino até o acesso a cursos de aperfeiçoamento/extensão para os educadores e a comunidade em geral. (FERNANDES, 1993; ORIÁ, 1997). Fundamental é que se trabalhe com a formação da consciência preservacionista pela via do conhecimento democratizante, que desvela a trajetória histórica e social da constituição do patrimônio cultural.

A preservação, por meio da participação social, constitui tarefa a ser exercida pela educação ao incentivar os alunos a preservar a sua história de vida e de seu grupo social, colaborando para a implementação de valores essenciais para a construção de sua cidadania. Nessa perspectiva, os estudos locais poderão exercer papel fundamental para o ensino/aprendizagem de História, contribuindo para a conscientização dos futuros cidadãos em termos da preservação da memória coletiva.
Embora no caso analisado o projeto não tenha alcançado a direção pretendida, especialmente no que se refere à socialização do conhecimento produzido, esse é o real sentido de uma política cultural preservacionista: que recusa a visão de cadastro, de conservação. Investir apenas nessa possibilidade é como negar a fruição do tempo, a dinâmica social; significa valorizar o processo de fossilização, voltar as costas para o campo das possibilidades, negar a criatividade do ser humano ao resolver as dificuldades cotidianas; apostar no imutável enquanto forma de poder, recusar a leitura das lacunas, a proposta de indagações aos "lugares de memória" enquanto ritos de passagem dos diferenciados grupos sociais.

A clareza sobre a elaboração de uma política pública de preservação funda-se na relação entre o patrimônio cultural e a possibilidade de sua construção imaginária, os diferentes usos a que se pode prestar, as diferenciadas condições que a desigualdade social impõe na sua composição, os objetivos implícitos em sua constituição, as possibilidade ilimitadas de sua existência no contexto da indústria cultural e os parâmetros estético-filosóficos que regem sua constituição, preservação e difusão (CANCLINI, 1994).

Essas questões articulam-se com a reflexão sobre a possibilidade de formulação e fruição de políticas culturais de inspiração democrática, as quais se amparam no princípio da 
participação dos diferenciados setores sociais na vida cultural das cidades, valorizando diferentes experiências e capacidades de expressão, oportunizando a expansão da criatividade e o fortalecimento da consciência crítica. Entretanto, tais perspectivas só são exeqüíveis, pela democratização dos espaços institucionais, pelo fortalecimento da sociedade civil como pregado pela perspectiva gramsciana, isto é, pela contemporaneidade com o contexto social, pela sintonia com a variedade e a dinâmica dos movimentos da sociedade civil.

Tal postura remete para a questão da cidadania, em função de que é por meio da memória, do conhecimento e compreensão de suas marcas, no entrelaçamento das oposições popular - erudito, dos símbolos paradigmáticos de realidades patrimoniais (nacional/regional/ local) que, ao mesmo tempo em que se constrói a qualidade de ser cidadão, encerra-se o direito de ser cidadão, pelo conhecimento de valores e significados impostos a determinada identidade cultural.

Nesse sentido, exercer a cidadania encerra não só o acesso à memória como à ação de selecionar e se apropriar de seus significados. Assim, cabe ao Estado - governo e sociedade civil - garantir, também, o acesso aos direitos individuais e coletivos e a vigência da pluralidade cultural, uma vez que a consciência de pertença do cidadão a determinado grupo social revela uma concepção de patrimônio cultural na forma como é constituído, conservado, defendido, e considerado representativo da vida em sociedade.

\section{REFERÊNCIAS BIBLIOGRÁFICAS}

1 CAMPOS, Pedro M. Esboço da historiografia brasileira. In: GLENISSON, Jean. Iniciação aos estudos históricos. 5. ed. São Paulo: Bertrand Brasil / DIFEL. p.205-294.

2 CANCLINI, Néstor García. O patrimônio cultural e a construção imaginária do social. Revista do Patrimônio Histórico e Artístico Nacional, Brasília, $\mathrm{n}$. 23, p. 95-111, 1994.

3 FERNANDES, José Ricardo O. Educação patrimonial e cidadania: uma proposta alternativa para o ensino de História. Revista Brasileira de História, São Paulo, v. 13, n. 25/26, p. 265-276, set./ago. 1992/1993.

4 GOHN, Maria da Glória. Movimentos sociais e educação. São Paulo: Cortez, 1992. 117p.

5 GUTIERREZ, Ramón. História, memória e comunidade: o direito de patrimônio construído. In: SÃO PAULO. Secretaria Municipal da Cultura. O direito à memória: patrimônio histórico e cidadania. São Paulo: Departamento do patrimônio histórico, 1992. p. 121-127. 
6 JEUDY, Henry-Pierre. Memórias

219-243, set.fev. 1989/1990. do social. Rio de Janeiro : Forense, 1990. $146 \mathrm{p}$.

7 LE GOFF, Jacques. História e memória. Campinas: UNICAMP, 1990. 553p.

8 . A História Nova. São Paulo: Martins Fontes, 1993. 96 p.

9 MAGNANI, José Guilherme C . Pensar grande o patrimônio cultural. Lua Nova, [19-- p. 62-67.

10 MANIQUE, Antônio Pedro; PROENÇA, Maria Cândida. Didáctica da História: patrimônio e História local. Lisboa: Texto Editora, 1994. $108 \mathrm{p}$.

11 MARSHAL, I. H. Cidadania, status e classe social. Rio de Janeiro: Zahar, 1967.

12 NORA, Pierre. Entre memória e História. Projeto História, São Paulo, n. 10, p. 6-39, dez. 1993.

13 ORIÁ, Ricardo. Memória e ensino de História. In: BITTENCOURT, Circe. O saber histórico na sala de aula. São Paulo: Contexto, 1997, p.265-276.

14 RODRIGUES, Marly. De quem é o patrimônio? um olhar sobre a prática preservacionista em São Paulo. Revista do Patrimônio Histórico e Artístico Nacional, Brasília, n. 24, p. 195-203, 1996.

15 SAMUEL, Rafhael. História local e História oral. Revista Brasileira de História. v.9, n.19, p. 